\title{
FALEMOS DE GÊNERO PELO BEM DE NOSSAS MENINAS
}

\author{
Let's talk about gender for the sake of our girls
}

\author{
Martha Júlia MARTINS \\ Universidade Federal de Roraima \\ marthajumartins@gmail.com \\ https://orcid.org/0000-0003-1547-827X
}

Enquanto escrevo essas linhas, leio uma notícia de que os holandeses comemoram a decisão do governo de excluir informações relacionadas a gênero nos documentos de identificação a partir de 2025. Parece banal, mas a medida oferece àqueles que não se identificam com seu sexo biológico viverem sem o constrangimento de serem obrigados a identificarem-se como homem ou mulher. Veja bem, em nenhum momento estou dizendo que o sexo biológico não existe ou que você deve abdicar de sua heterossexualidade monogâmica para viver um novo relacionamento poliamor. O que está sendo dito aqui é que ser reconhecido da forma como melhor lhe aprouver deveria ser garantido como um direito individual inalienável em uma sociedade regida por preceitos democráticos.

Também não está sendo dito aqui que na Holanda não existe desigualdade de gênero, pois a estrutura de poder que dá abrigo ao patriarcado sempre encontra um jeito de manifestar-se em algum grau nas sociedades de uma forma geral; na holandesa não seria diferente. Exemplo disso é a notícia ${ }^{1}$ recente de que a Universidade Técnica de Eindhoven dará prioridade para contratar apenas mulheres no ano de 2021, em busca de um maior equilíbrio entre profissionais homens e mulheres. A reportagem por si só já demonstra que se há a necessidade da implantação de tal medida é porque mulheres não ascendem tão facilmente em áreas técnicas, como desejado.

Nesse sentido, é importante relembrar o que diz Saffioti (2015, p. 107): “nenhum(a) estudioso(a) sério(a) consideraria igual o patriarcado reinante na Atenas clássica ou na Roma antiga ao que vige nas sociedades urbano-industriais do Ocidente". Seguindo o mesmo raciocínio, Butler (2017, p. 21) aponta que "a noção de um patriarcado universal

\footnotetext{
${ }^{1}$ Disponível em: <https://brasil.elpais.com/brasil/2019/07/03/ciencia/1562140283_687546.html>. Acesso em: 14 jul. 2020.
} 
tem sido amplamente criticada em anos recentes, por seu fracasso em explicar os mecanismos de opressão de gênero nos contextos culturais concretos em que ela existe". Entendo com isso que as opressões do patriarcado possuem várias nuances que se perpetuam de variadas formas, em diversos contextos. Embora muitos avanços no quesito igualdade de gênero tenham sido alcançados, ainda há muito a ser feito, principalmente agora que acompanho estupefata a uma guinada conservadora que atinge em cheio muitos países democráticos mundo afora, entre eles o Brasil.

A ascensão de Jair Bolsonaro, figura conservadora da ultradireita brasileira, coincide com a confusão generalizada entre Estudos de Gênero e ideologia de gênero. O primeiro é campo do conhecimento interdisciplinar e o segundo não encontra quaisquer precedentes na academia e que de tão absurdo, mais parece teoria conspiratória de série televisiva. Ainda assim, a chamada ideologia de gênero parece ter adquirido muitos adeptos ao longo do caminho. Em 2004, surgiu a proposta da Escola sem Partido, movimento político que manifesta-se contrariamente ao que vem sendo chamado de doutrinação ideológica nas escolas, e portanto, empenhou-se na criação de um projeto que visava limitar a atuação dos professores, que eram acusados de influenciarem os alunos com suas crenças e ideologias que, de um modo geral, coincidem com as pautas da esquerda. O problema não consistiu em influenciar alunos com uma ideologia de direita ou de extrema direita, o problema foi influenciar alunos com um pensamento tido como de esquerda. O movimento incentivou seus adeptos a filmarem os professores tidos como doutrinadores, durante o exercício de suas funções, e ainda promoveu uma discussão em torno da redação do projeto de lei da Escola sem Partido, proibindo quaisquer discussões em torno da concepção de gênero.

Imediatamente, o termo gênero passou a funcionar como um gatilho nacional coletivo que aciona um fiscal da moral alheia em todo e qualquer indivíduo que acredita saber do que se trata gênero e que logo associa o termo à destruição da família tradicional brasileira. Leis de proibição ao termo reverberam país afora, como no caso do estado de Roraima e a criação da lei n. ${ }^{\circ} 1245$, de 02 de fevereiro de 2018, que proibiu qualquer menção às discussões de gênero nas escolas públicas e particulares do estado. A lei foi revogada um ano depois e substituída por uma lei mais flexível que permite tratar sobre a violência de gênero nas escolas do estado, tornando a lei anterior sem efeito (SOUZA, 
2020). Considerada uma vitória pelos movimentos feministas e setores mais progressistas, decisão recente do STF (Supremo Tribunal Federal) decidiu pela inconstitucionalidade do projeto Escola sem Partido reiterando a inconstitucionalidade de leis que proíbam a abordagem de Estudos de Gênero nas escolas e universidades.

Portanto, entender gênero e falar sobre isso nas escolas, nas universidades e nas demais instituições públicas que executam políticas públicas governamentais é importante para reconfigurar as narrativas que culpabilizam e estigmatizam as mulheres, além de, na prática, combater violências de gênero. Falo de violências no plural, porque a violência pode ser física, psicológica, mais agressiva, mais sutil, contra mulheres negras, trans, indígenas, etc. Vou além...compreender gênero sob a perspectiva dos Estudos de Gênero beneficia não apenas mulheres e indivíduos pertencentes à comunidade LGBTQ+, mas também, homens que eventualmente possam vir a sofrer com padrões de masculinidade tóxicos, impostos por um sistema de poder patriarcal, branco, heteronormativo. Afinal de contas, quem nunca escutou a máxima de que "homem de verdade não chora", típica de uma sociedade que nega aos homens, héteros ou não, a demonstração livre de afeto. Repensar a forma como queremos lidar com os padrões de gênero que nos são impostos por essa lógica patriarcal requer o difícil caminho de nos desconstruirmos. É importante pensar gênero refletindo sobre o acúmulo de opressões com base na raça, no gênero e na classe do indivíduo. Só assim teremos a chance de combater desigualdades estruturais.

O termo gênero surge pela primeira vez em 1968, na obra de Robert Stoller, entretanto só ganha destaque com o trabalho de Rubin ([1975] 2017). Aqui, gênero é entendido como uma construção social que não se dissocia de sexo (SAFFIOTI, 2015). Com isso quero dizer que o sexo biológico do indivíduo não é renegado por estudiosos e pesquisadores da área, como muitos fazem parecer. O que está sendo questionado é: (i) a negação de outras identidades além daquelas preestabelecidas pela genética; (ii) a crença de que somos biologicamente determinados a seguir certos comportamentos com base em nosso sexo biológico; e (iii) o contrato heteronormativo que impede indivíduos de exercerem suas sexualidades conforme acharem melhor. Em outras palavras, o que está sendo dito aqui é que o sexo biológico do indivíduo não deve ser fator determinante para decidir a forma como esse mesmo indivíduo decida viver sua sexualidade, pois o sexo biológico não deve ser o balizador das inúmeras formas de sexualidade disponíveis. 
Nem mesmo estou dizendo que quem nasce cis e se identifica com o sexo biológico ao qual nasceu deve deixar de identificar-se com esse sexo. Assim, ao nascer indivíduo do sexo masculino, nada impede que esse mesmo indivíduo seja heterossexual e relacione-se com mulheres; ou que nascendo do sexo masculino, queira relacionar-se com indivíduos do seu mesmo sexo biológico; ou que ainda nascendo indivíduo do sexo masculino, queira ser transexual e relacionar-se com mulheres ou homens. As configurações são muitas, assim como o preconceito e a intolerância daqueles que não entendem que o fato de um indivíduo ser heterossexual não lhe confere o direito de decidir outras configurações de família e de sexualidade.

A incompreensão do que é gênero e porque os padrões de masculinidade e feminilidade patriarcais precisam ser combatidos está diretamente relacionado às recomendações da UNESCO (Organizações das Nações Unidas para a Educação, a Ciência e a Cultura) de promover o ensino de educação sexual nas escolas para informar jovens e adolescentes de possíveis situações de abuso sexual e demais violências de gênero. Como demonstra Biroli (2018, p. 138) "violências e constrangimentos se organizam segundo convergências de gênero, sexualidade, classe e raça. Não é apenas a ação discriminatória, mas também a inação do Estado que dá livre curso às formas múltiplas de violência estrutural". Sendo assim, discutir gênero nas escolas e universidades é de considerável relevância para o bem-estar dos indivíduos em sociedade.

Engana-se quem acredita que a educação sexual induz nossas crianças e adolescentes a promiscuidade. Aliás, o que é promiscuidade e quem define isso? Educação sexual conscientiza sobre a importância do uso de preservativos, sobre doenças sexualmente transmissíveis e sobre a importância de respeitar os limites do próprio corpo. O que as pessoas não parecem entender é que promover a desinformação possui estreita ligação com aqueles que são coniventes e/ ou praticantes das inúmeras violências de gênero, sejam elas física, psicológica ou verbal. A quem interessa negar o devido ensino de educação sexual nas escolas, senão àqueles que pensam em controlar e punir os corpos de mulheres, gays, lésbicas e trans. Afinal, quem se beneficia da ignorância de nossos jovens?

O controle da sexualidade sempre existiu e quando foi conveniente ao Estado e à Igreja da Idade Média, casas de prostituição foram permitidas para que mulheres fossem 
oferecidas como prostitutas, para que se evitasse a prática da sodomia entre homens e se estimulasse as relações heteronormativas, uma vez que relações homoafetivas ou mesmo o controle de natalidade praticado pelas mulheres da época desestruturavam a lógica familiar burguesa, em formação, centrada no poder do pai. É importante lembrar que estamos falando do período em que o nascimento de uma criança era a garantia de um trabalhador a mais à disposição do sustento familiar e do capital (FEDERICI, 2017).

Ao suscitar pautas conservadoras que subtraem os direitos das mulheres, perdemos como sociedade, uma vez que amplos direitos reprodutivos e garantias de segurança e bem-estar às mulheres também são indicadores de qualidade de vida e desenvolvimento humano. A extrema-direita no Brasil se baseia em princípios patriarcais antigos, gestados muito antes da ascensão de Jair Bolsonaro à presidência do Brasil, é verdade, mas com raízes e marcas profundas na sociedade até hoje. A tentativa de criminalizar mulheres, seus corpos, seus afetos e suas sexualidades faz lembrar o período conhecido na Europa como o período da caça às bruxas, entre os séculos XV e XVII, em que se negava a essas mulheres o direito de serem curandeiras, parteiras ou mesmo sensíveis ao próprio corpo e reprodução (FEDERICI, 2017). Para Federici (2017, p. 326) “parece plausível que a caça às bruxas tenha sido, pelo menos em parte, uma tentativa de criminalizar o controle da natalidade e de colocar o corpo feminino - o útero - a serviço do aumento da população e da acumulação da força de trabalho". Por analogia, a mesma lógica da sociedade feudal que condenava as mulheres à fogueira, hoje nos pune por meio de crenças limitadoras e por falta de políticas públicas estatais que garantam proteção e ampla liberdade de direitos.

Assim, não causa espanto nenhum o fato de avançarmos tão pouco em pautas tão importantes no Brasil. Se somos estupradas, é porque pedimos ou porque não usamos a roupa mais adequada. Se somos traídas, é porque não servimos aos nossos maridos como o contrato matrimonial assim nos diz. Se engravidamos, somos culpadas, se não engravidamos, também somos culpadas. Enquanto a vizinha Argentina discute e leva para votação a pauta do aborto pela segunda vez, aqui no Brasil sequer começamos a pensar sobre discutir em sociedade as possibilidades de interrupção da gravidez, sem punições, sem preconceitos, mas como uma política de saúde pública que garanta a proteção de mulheres.

A ideologia de gênero - que em nada se assemelha aos Estudos de Gênero - é uma 
criação fantasiosa do que esse segmento ultra conservador acredita ser educação sexual e que não apresenta nenhuma conexão com o verdadeiro campo interdisciplinar a que se dedica o estudo da identidade e da representatividade de gênero. A ideia de que não devemos falar sobre sexualidade nas escolas serve apenas para proteger abusadores e reproduzir a lógica de violência e discriminação contra mulheres. Além disso, a ideia de que não falar de sexo e sexualidade retarda ou desincentiva os jovens a descobrirem sua sexualidade tem pouco amparo na realidade dos fatos, uma vez que sexo e a descoberta desse sexo é um processo que inevitavelmente acontece para todo mundo; cabe aos educadores e aos pais, o cuidado em orientar esses jovens durante esse processo de descoberta, de forma a promover essa transição com a responsabilidade e os cuidados necessários.

O conservadorismo tacanho e hipócrita que assola o nosso país finge que só falar de gênero é ideológico. Ideológico também é não falar de gênero. Igualmente ideológico é ser conivente com a misoginia, com o machismo e com os padrões limitadores de gênero. Sendo assim, sejamos ideológicos, falemos de gênero, pelo bem de nossas meninas.

\section{REFERÊNCIAS}

BIROLI, F. Gênero e desigualdade: limites da democracia no Brasil. Boitempo, 2018.

BUTLER, J. Problemas de Gênero. Feminismo e Subversão da Identidade. Civilização Brasileira, 2017.

FEDERICI, S. Calibã e a Bruxa. Elefante, 2018.

RUBIN, G. Políticas do Sexo. São Paulo: Ubu Editora, 2017

SAFFIOTI, H. Gênero, Patriarcado, Violência. São Paulo: Fundação Perseu Abramo, 2015.

SOUZA, M. J. M. Feminismo e intolerância: uma análise das leis estaduais do estado de Roraima. Revista Letrônica. Porto Alegre, v.13, n.2, p. 1-12, abr-jun, 2020. 